\title{
Transformaciones en las relaciones de género-familiares y la agencia de campesinas indígenas cafetaleras en cooperativa
}

\author{
Transformations in the relations of gender-families and the indigenous \\ coffee farmers agency in a cooperative
}

Ana Georgina López Zepeda *

\begin{abstract}
Resumen
El presente artículo muestra algunos hallazgos respecto a las transformaciones familiares y de género de las últimas décadas en los ámbitos rurales, sustentada en la investigación realizada para mi tesis doctoral: "Campesinas indígenas cafetaleras en cooperativa: Violencias y alternativas de agencia. El caso del Ejido Zaragoza, Municipio de Ocosingo, Chiapas" la cual aborda diversas situaciones que atraviesan las mujeres en los ámbitos rurales y sus posibilidades de agencia al estar organizadas en cooperativa. Este trabajo tiene un enfoque de género y antropológico, apoyado en la etnografía y en la comprensión teórica de lo que viven las mujeres en estos contextos. La investigación constituye un aporte con relación a las dinámicas rurales de las últimas décadas de las familias indígenas, que se expresan en conjunto con las alternativas de generar ingresos extra-domésticos y construir capacidades individuales y colectivas a través de la cooperativa.
\end{abstract}

Palabras clave: género, generación, agencia, cooperativa, ruralidad.

\begin{abstract}
The present article retrieved some of the findings in relation to the family and gender transformations of the last decades in the rural areas, according to the collected in the research of my doctoral thesis: "Indigenous peasant coffee cooperative: Violence and alternatives of agency. The case of the ejido Zaragoza, municipality of Ocosingo, Chiapas", which deals with various situations that women in rural areas and their possibilities of agency, to be organized into cooperative. This work has a gender and anthropological approach, based on the ethnography and in the theoretical understanding of what women in these contexts. The research is a

* Dra. en Ciencias Sociales con orientación en Antropología por el Centro de Investigaciones y Estudios Superiores en Antropología Social (CIESAS). Académica del Instituto Tecnológico de Estudios Superiores de Occidente (ITESO), Jalisco, México. Email: anageo@iteso.mx
\end{abstract}


contribution in relation to the rural dynamics of the last decades of indigenous families, which are expressed in conjunction with the extra domestic alternatives to generate income and build individual and collective capacities through the cooperative.

Key words: gender, generation, agency, cooperative, rurality.

Fecha de recepción: 30 de mayo 2017

Fecha de aprobación: 30 de mayo 2018

\section{Introducción: Las transformaciones en los ámbitos rurales}

Desde la década de los setenta, las familias y los grupos domésticos en el campo ya no han basado su subsistencia sólo en la producción agrícola de autoconsumo, sino que se han incorporado una serie de actividades que implican una mayor participación femenina en la economía familiar.

En México existe el interés de visibilizar el trabajo de las mujeres en la producción campesina no remunerada a través de investigaciones antropológicas que abordaron la feminización del trabajo en conjunto con la reestructuración de los mercados laborales y su incidencia en las unidades domésticas, así como la situación de precariedad y emergencia en el México rural.

Según Benería (1982) y González Montes (1993) en las décadas de los ochenta y noventa, las investigaciones se centraron en las temáticas de la sobrevivencia familiar ante la amplia gama de actividades económicas, remuneradas y no remuneradas de las mujeres rurales, la diversificación de las economías campesinas, la división sexual, de género y generacional del trabajo, las cargas de trabajo de las mujeres y sus estrategias.

Una de las contribuciones fue la propuesta por González Montes (2002) en la ruptura de un modelo familiar homogéneo y de ausencia de conflicto, para más bien mostrar la diversidad de dinámicas familiares en la ruralidad. Entre éstas, las condiciones de movilidad en las jerarquías de autoridad y poder entre las generaciones y las diferencias de los recursos socioeconómicos y de capacidades por género.

También, durante los noventa, los estudios se enfocaron en el análisis de los procesos desencadenados por la implantación de un modelo neoliberal y las nuevas políticas y programas gubernamentales (Marroni, 1995; Mummert, 1995). Es decir, se incluyeron estudios sobre derechos jurídicos, acceso al mercado informal y participación en los gobiernos comunitarios.

Así pues, los aportes de estos estudios visibilizaron un conjunto de procesos y transformaciones en el campo en las últimas décadas. A pesar de que las condiciones de pobreza y desigualdad han prevalecido, ahora también las mujeres cuentan con una mayor participación en la toma de 
decisiones y en su papel comunitario. Como plantea Ortner (1984), las estructuras sociales y la normatividad cultural no son las únicas fuerzas que moldean o determinan a los individuos. Influyen, pueden tener un gran peso, pero no determinan a la experiencia y agencia individual/colectiva por la cual los sujetos construyen su historia.

González Montes (2002), indica que la inclusión femenina a los proyectos productivos -como las cooperativas-, significa una dinámica compleja que abre dilemas fundamentales para el desarrollo de las campesinas. Por un lado, contempla al ingreso femenino como fundamental para que las mujeres tengan mayor peso en las decisiones familiares y para tener acceso a la movilidad/sociabilidad, libertad y gestión. Por otra parte, todo esto genera conflictos intrafamiliares e intracomunitarios que las pueden poner en riesgo y desventaja.

La noción de emergencia se refiere a un surgimiento de diversas condiciones, transiciones y dinámicas para las mujeres en la ruralidad, así como de distintas respuestas ante estas. Por ejemplo, la emergencia se hace evidente en el mayor acceso y conexión entre las localidades urbanas y rurales, la cobertura de servicios básicos y la agricultura, que ya no solamente se concibe como lo agropecuario, sino que integra otra serie de prácticas como la movilización de los recursos, la comercialización, la distribución y organización. De acuerdo con Boaventura De Sousa (2000), la emergencia sitúa la ampliación simbólica de los saberes, prácticas y modos que identifican posibilidades.

Como he señalado, la creciente incorporación de las mujeres al mercado laboral ha sido uno de los factores más determinantes para generar cambios en las relaciones de género, aún a pesar de que persistan desigualdades sociales, económicas y políticas. Se ha presentado un proceso de diversificación ocupacional dinámico, lo cual ha significado para ellas una mayor participación en la economía familiar. Esta situación concuerda con De Sousa (2000), dado que la inclusión femenina ha implicado una emergencia, un sentido de cambio social y de ampliación simbólica de los modos de vida.

Este autor pone énfasis en que la emergencia actúa sobre las posibilidades y sobre las capacidades, así como en los principios de acción que promueven la realización de esas condiciones. Igualmente, analiza las relaciones contra-hegemónicas y las respuestas de los sujetos concebidos y clasificados en "los márgenes" por las relaciones de poder y las secuelas del colonialismo, situación que ocurre con las mujeres campesinas indígenas, ya que se les ha desvalorizado por su condición de género-étnica y de clase social.

Ahora, ¿Cuáles son las principales transformaciones en la ruralidad? De acuerdo con Echeverri y Pilar (2002), y Cernea (1995), las principales son las siguientes:

a) Cambios productivos: diversificación de actividades económicas que trascienden la agricultura: agroindustria, ecoturismo, producción artesanal, mercado informal, organizaciones cooperativas. 
b) Cambios sociodemográficos: migración nacional e internacional que provocan cambios del mercado de trabajo rural, así como transformaciones en las relaciones de género y familiares.

c) Reformas agrarias: con las diversas reformas al artículo 127 de la Constitución Federal se facilita la transacción y aprovechamiento del suelo con fines empresariales.

d) Descentralización política: las reformas al artículo 115 constitucional, realizadas desde principios de 1980 referentes al incremento en las atribuciones de los municipios y en sus recursos económicos, así como la tendencia a fortalecer el federalismo.

e) Acceso a la tecnología: se ha acrecentado la transferencia y el uso de la tecnología hacia los lugares rurales.

f) Desarrollo rural sustentable: inclusión de programas y perspectivas orientadas a la procuración, conservación y uso adecuado de los recursos naturales.

g) Incorporación de la perspectiva de género al desarrollo rural: inclusión de programas de desarrollo rural que influyen en la dinámica cultural de las normas, creencias y valores de la vida comunitaria.

h) Procesos de globalización, reformas económicas que afectan o no la producción agropecuaria, los subsidios gubernamentales y la reestructuración de empresas estatales y privadas que apoyan los proyectos en el ámbito rural.

\section{Relaciones de género, étnicas y generacionales}

\subsection{Género-etnia}

Joan Scott (1986) define al género como un elemento constitutivo de las relaciones sociales, basadas en las diferencias sociohistóricas percibidas entre los sexos. Para esta autora, el género es una herramienta útil para el análisis histórico y comprende cuatro elementos interrelacionados ${ }^{1}$ que contemplan la dimensión simbólica, la dimensión social y la dimensión individual. Desde mi punto de vista, estas dimensiones aún proporcionan pistas para el análisis de las relaciones de género en los contextos rurales, sobre todo en comprender como se ha utilizado a la diferencia sexual como una desventaja en diversos ámbitos de la vida, como lo es la organización familiar comunitaria entrelazada a la naturalización de órdenes en base al sexo. Por ejemplo, el vínculo entre el cuerpo femenino con la reproducción, la maternidad, las tareas domésticas, entre otras.

Entiendo al género como el conjunto de prácticas incorporadas en la experiencia del sujeto, a raíz de lo significado o resignificado como diferencia sexual, que inciden en el orden social establecido. Lamas (1995) refiere que lo que motiva al uso de esta categoría como herramienta

\footnotetext{
1 Scott (1986) señala a: 1) Los símbolos y mitos culturalmente disponibles; 2) los conceptos normativos que manifiestan las representaciones de los significados de los símbolos; 3) las instituciones y organizaciones sociales de las relaciones de género: el sistema de parentesco, la familia, el mercado de trabajo segregado por sexos, las instituciones educativas, entre otras; y 4) la construcción de la identidad de género.
} 
de análisis es la necesidad de "desnaturalizar", deconstruir y resignificar las construcciones sociales e históricas para la transformación.

Ante ello, la perspectiva del feminismo comunitario ha puesto énfasis en analizar el sistema colonialista patriarcal, en recuperar como el feminismo no es una matriz individual de las mujeres, sino que hay diferencias en términos étnicos, raciales, de clase. Tal como señala Olivera (2001), el feminismo debe atender las violaciones a los derechos humanos, así como la lucha por los derechos sexuales-reproductivos -el aborto, el derecho a la opción sexual-, la reivindicación colectiva por usos y costumbres que no atenten contra sus derechos básicos, con relación a las múltiples formas y posiciones de ser mujer, que también se encuentran asociadas a las posiciones y formas de ser hombres.

Un aspecto que ha contribuido a los estudios de género sobre mujeres en las últimas décadas es incluir a las investigaciones sobre masculinidades. Es decir, entender las múltiples maneras de interrelación entre hombres y mujeres, hombres-hombres, mujeres-mujeres, entre otras, y como se expresan en las relaciones de poder. Por ejemplo, los hombres indígenas establecen relaciones y alianzas ${ }^{2}$ en lo familiar como en lo comunitario, que los benefician. Pero esto también tiene que ver con que ellos desarrollan un sentido de socialización distinta y otras cargas y quehaceres asumidos. Estas formas de poder se encuentran ancladas y establecidas en una política sexual, en donde la mujer es vista como "procreadora" o como un cuerpo estético erótico.

Ahora bien, como he señalado, la categoría de género debe entrelazarse con la de generación y la etnia, puesto que la violencia hacia la mujer no ocurre solamente por el hecho de ser "mujer", sino porque encarna una serie de posiciones en la organización social con múltiples desventajas.

La categoría de la etnia, según Barth (1976), se refiere a una apropiación y adscripción construida a través de la experiencia, constituida por la diferencia cultural que invoca a lo propio, a lo considerado como originario. Es una construcción sociocultural que involucra tanto a las características culturales y simbólicas, recreándose entre sí, a través de distintos mecanismos como los económicos, culturales, idiomáticos e ideológicos.

Como propone Marisol de la Cadena (1992) en Las Mujeres son más indias, la etnicidad conforma parte de un proceso histórico en dos niveles de las relaciones sociales: el de las interacciones sociales, y el del proceso político, micro-regional, regional y nacional de larga duración. Sin embargo, en este proceso han influido distintas coyunturas históricas opresivas y racistas en donde se ha redefinido la identidad étnica. Por ello, para dar cuenta de la etnicidad, se tiene que dar cuenta de las relaciones con la alteridad, que confrontan a lo étnico, así como situarlas en las dinámicas contextuales históricas y entender los diversos entrecruzamientos, entre el género, la generación y la organización familiar.

2 Lagarde (1992) refiere que las alianzas entre hombres son las alianzas históricas del poder masculino que encuentran su asiento en diversas formaciones socioculturales, ligadas a la violencia que se ejerce sobre las mujeres. 


\subsection{Las relaciones intergeneracionales y el parentesco}

Valderrama (2006) señala que la categoría de generación se refiere a la genealogía de personas que forman parte de la línea de sucesión anterior o posterior de un individuo de referencia. En la familia se dan una serie de relaciones intergeneracionales importantes que delimitan la reproducción o no reproducción de violencias, relaciones de poder o posibilidades de agencia entre las mujeres indígenas. La generación agrupa a los individuos según las relaciones que mantienen con sus ascendientes y sus descendientes, según la conciencia que tienen de pertenecer a una generación.

La noción de parentesco se deriva de pariente, del latín parens, que significa la relación de consanguinidad y de afinidad o alianza. Radcliffe-Brown (1974) refiere que es un sistema, una compleja red de relaciones de interdependencia entre las partes componentes de parentesco y afinidad.

Las relaciones de parentesco se han fundamentado en el Modelo Mesoamericano de Robichaux (1997), que se caracteriza por: a) la residencia patrivirilocal inicial de la pareja, b) familia extensa, c) último-genitura patrilineal en la herencia de la casa, lo que implica el cuidado de sus padres, d) familias extensas basadas en el lazo y herencia de tierra patrilineal. Estas características repercuten en las desigualdades que viven las mujeres indígenas rurales, ya que existe una distribución distinta del poder al interior de la familia, un aislamiento de las mujeres de la familia nuclear en las posibilidades de elegir y de movilizarse en otros espacios.

Freyermuth (2004) analiza los factores de riesgo en asociación con el parentesco y la organización familiar comunitaria. Entre sus observaciones, encontró prácticas de subordinación desde edades tempranas que favorecían abusos, sumisiones, golpes, humillaciones, no únicamente de parte de la pareja, sino de suegras/os, cuñadas/os, entre otros:

Desde tempranas edades, las mujeres interiorizan, por las prácticas educativas familiares, la necesidad de ser sumisas y obedientes y de no manifestar sus malestares o preocupaciones. La integración de estas representaciones se realiza merced a procedimientos correctivos severos, muchos de los cuales implican daños físicos permanentes. Estas experiencias previas al matrimonio posibilitan relaciones de violencia y, sobre todo, una actitud pasiva frente a la misma, no sólo de quien recibe violencia, sino de la familia e incluso de la comunidad (Freyermuth, 2004: 83-84).

Así pues, las niñas indígenas son educadas para reproducir los patrones de género, sobre todo en las responsabilidades del hogar y en el cuidado de los hermanitos. Ante ello, Freyermuth (1997) argumenta que las violencias e inequidades estructurales tienen que ver con la violación reiterada y sistemática de los derechos humanos de las mujeres, encubiertas en normas legitimadas por los miembros de las comunidades. Este planteamiento abre pistas para el análisis, ya que las violencias hacia las mujeres indígenas no solamente se manifiestan en formas diversas y con variados matices, sino que tienen que ver con las situaciones reiteradas y 
recursivas, que las afectan en aspectos nucleares de sus vidas, como en las continuas amenazas a su libertad, las humillaciones, el control a su movilidad y la imposibilidad de seguirse desarrollando en otros ámbitos.

Ahora bien, ni las características, ni las repercusiones son estáticas, sino que se encuentran en constante movimiento. Como analiza Patricia Arias (2009), las familias en los contextos rurales han experimentado diversas transformaciones a raíz de la disputa por la tierra, la migración, la falta de oportunidades en el empleo, la crisis en el campo, el desarrollo de las agroindustrias, la creciente participación femenina en la economía familiar y el cambio de los procesos agrícolas a una rotación múltiple de empleos que ya no giran solo en torno del autoconsumo, lo cual conlleva a cambios en las relaciones de género.

Igualmente, las transformaciones se han asociado con la duración y la reducción del tiempo de la residencia patrivirilocal, pues la organización de la familia recurre a otro tipo de estrategias socioeconómicas que implican una serie de procesos diversos que abren otro tipo de alternativas. Así pues, las mujeres indígenas son más partícipes de la economía familiar y son parte de otra generación en que se van redefiniendo las relaciones entre los géneros y las generaciones, los tipos de organización familiar, la distribución del poder al interior y las diversas maneras de vivir la conyugalidad.

\section{Estrategia Metodológica: Etnografía y entrevistas}

Observar y analizar las experiencias y prácticas de las campesinas indígenas que se entretejen en los ámbitos rurales implica un gran desafío metodológico, ya que se requiere de la propia implicación y de ganarse la confianza a través del trabajo y la convivencia cotidiana compartida. Para dar cuenta de lo anterior, utilicé el método etnográfico, a través de la observación participante de prácticas e interacciones cotidianas y de la recuperación de narrativas de las campesinas en torno a sus experiencias de violencias, restricciones, acceso a recursos, posibilidades y agencia. También rescaté algunas diferencias en torno a sus ámbitos de acción, entre campesinas pertenecientes a cooperativas cafetaleras y campesinas no pertenecientes ${ }^{3}$.

Para mi trabajo de campo preparé una guía de estudio de caso. Para Martínez Carazo (2011) ésta constituye una estrategia de investigación dirigida a comprender las dinámicas presentes en ciertos contextos, la cual podría tratarse del estudio de uno o varios casos a través de la evidencia empírica de campo. Esta herramienta se basa en la recopilación de información sobre la comunidad, el grupo o los sujetos a lo largo de un tiempo considerable.

Orienté el estudio de caso hacia tres ámbitos: la organización comunitaria del ejido ${ }^{4}$, la cooperativa y los sujetos de análisis. A través de entrevistas, recuperé también trayectorias de

${ }^{3}$ Esto con la finalidad de recuperar las diferencias de las campesinas organizadas en cooperativa y de analizar si en realidad existen diferencias sustanciales con relación a otras mujeres no organizadas.

${ }^{4}$ Por ejido se entiende el núcleo de población del ejido, el que tiene personalidad jurídica y es titular de derechos agrarios, reconocidos por resolución presidencial restitutoria o de confirmación, sobre sus tierras y como unidad de producción cuenta con órganos de decisión, ejecución y control, que funcionan de 
vida de las mujeres campesinas. Las trayectorias permiten comprender el ámbito de la experiencia acumulada de las mujeres, los momentos más cruciales de sus vidas, sus decisiones y sus aprendizajes.

\subsection{Localidad de estudio: El ejido Zaragoza}

La recopilación etnográfica en este ejido fue durante mediados de noviembre 2013 a mayo de 2014. Una vez que llegué al ejido, establecí contacto con Anita Vázquez, representante de la cooperativa Nich Capeel, y Francisco, director de la Sociedad de Productores Orgánicos de la Selva Lacandona (SPOSEL) para que me dieran su permiso de realizar trabajo de campo en la comunidad y en sus instalaciones. Les dije que era antropóloga y que estaba haciendo una investigación sobre cooperativas de café de mujeres, a lo que ellos respondieron que les interesaba, ya que justo estaban promoviendo más su inclusión.

El ejido Zaragoza, se encuentra en la región Tumbo-Nahá, Municipio de Ocosingo, en el Estado de Chiapas, en el sureste mexicano. Se hacen cuatro horas y media de camino en camioneta de redil, trayecto en el cual conviví con campesinos tzeltales los cuales me recibieron amables, gracias a que les dije que iba con la representante Anita Vázquez. Cuando llegué al ejido, me dejaron directo en las instalaciones de Nich Capeel, las cuales abarcan un pequeño módulo, que consiste en un espacio-oficina pequeña, seguida de un cuarto para las actividades de las mujeres (tostado, molido y envasado de café) con unos anaqueles de comercialización del producto. Estas instalaciones se encuentran al lado de las instalaciones y la bodega de SPOSEL, en donde trabajan los hombres socios de la cooperativa y las autoridades ejidales.

La estrategia para acceder a las campesinas en el ejido fue estar la mayor parte del día en el módulo de las instalaciones, ya que este módulo, por su ubicación céntrica en el ejido reunía a muchas personas de la comunidad, así como me permitía comprender otras dinámicas, como la relación de las mujeres de Nich Capeel con los miembros de SPOSEL, con las mujeres que no pertenecían a la cooperativa, así como asambleas y reuniones comunitarias. Además de las instalaciones de la cooperativa y los hogares, otros de los lugares donde realicé etnografía fueron: la esquina donde se agarra el internet, la cancha de fútbol, el patio de la escuela secundaria y en algunas celebraciones religiosas de los sábados y domingos.

\subsection{Elección de sujetos de análisis}

Respecto a la elección de los casos de mujeres para la investigación, después de la inmersión al campo, fui conociendo a profundidad los casos de las campesinas indígenas. Para elegir, tomé en cuenta el criterio de selección de muestra teórica, es decir, un muestreo intencionado que representa a los sujetos de una situación en particular (Glaser y Strauss, 1967). En este caso, que cumplieran con los siguientes requisitos:

acuerdo con los principios de democracia interna, cooperación y autogestión conforme a sus tradiciones y costumbres (Ruiz, 1987: 236). 
- Campesinas de 17 a 60 años pertenecientes a cooperativas cafetaleras integradas por mujeres.

- Campesinas de 17 a 60 años no pertenecientes a cooperativas cafetaleras.

Al principio no consideré a las mujeres más jóvenes, pero en el trabajo de campo me pareció pertinente mostrar las diferencias en las experiencias de vida y los tipos de violencias que se encuentran asociadas a los ciclos de vida.

Los criterios de selección responden a los objetivos de la investigación, en este caso, saber cuáles eran las diferencias de las campesinas organizadas en cooperativa y analizar en contraparte a las que no estaban organizadas. Así mismo, busqué que fueran casos en diversas etapas de los ciclos domésticos, para ver si también la generación de recursos y posibilidades se asociaba a los distintos momentos de vida de las mujeres. En total, fueron 19 mujeres, que aparecen en el siguiente cuadro con seudónimo.

Tabla 1. Concentrado de campesinas entrevistadas en el ejido Zaragoza

\begin{tabular}{|c|l|c|c|c|c|}
\hline & Nombre & Edad & Estado civil & Cooperativa & Escolaridad \\
\hline 1 & Karla & 17 años & Soltera & & Secundaria \\
\hline 2 & Valentina & 17 años & Soltera & & Primaria \\
\hline 3 & Catalina & 21 años & Unión conyugal & Nich Capeel & Secundaria \\
\hline 4 & Mina & 21 años & Soltera & & Secundaria \\
\hline 5 & Mary & 22 años & Unión conyugal & & Primaria \\
\hline 6 & Aurora & 25 años & Soltera & Nich Capeel & Secundaria \\
\hline 7 & Damiana & 26 años & Unión conyugal & & Primaria \\
\hline 8 & Eugenia & 29 años & Separada & & Primaria \\
\hline 9 & Lucrecia & 34 años & Separada & & Primaria \\
\hline 10 & Anita & 34 años & Separada & Nich Capeel & Secundaria \\
\hline 11 & María Alex & 37 años & Unión conyugal & Nich Capeel & Primaria \\
\hline 12 & Valentina & 40 años & Separada & Nich Capeel & Primaria \\
\hline 13 & Macaria & 40 años & Unión conyugal & & Primaria \\
\hline 14 & Consuelo & 43 años & Unión conyugal & Nich Capeel & Primaria \\
\hline 15 & Elena & 46 años & Separada & Nich Capeel & Secundaria \\
\hline 16 & Rumina & 46 años & Viuda & Nich Capeel & 4to. Primaria \\
\hline 17 & Lupe & 48 años & Separada & Nich Capeel & Primaria \\
\hline 18 & Candelaria & 50 años & Viuda & Nich Capeel & 3ro. Primaria \\
\hline 19 & Alicia & 62 años & Viuda & Nich Capeel & 2do. Primaria \\
\hline
\end{tabular}

Fuente: Elaboración propia 
La guía de entrevista, integra un guion temático que me sirvió de referencia, ya que no siempre seguí el mismo orden. Igualmente, algunas de las cuestiones orientaban a otras más interesantes o significativas que no había contemplado o que me brindaban más pistas para el análisis. Después del encuadre, recuperaba los datos generales, -nombre, edad, estado civil, escolaridad, ocupación, lugar de origen y de residencia y si pertenece a cooperativa o no-. La guía en general abarcó los siguientes rubros:

1. Datos familiares (número de miembros en la familia, relación con ellos, lazos más importantes, prácticas alrededor de la organización familiar).

2. Prácticas económicas al interior de la familia (quienes se encargan del dinero, como lo hacen).

3. Hábitos y actividades regulares de trabajo en el hogar y en el campo según los ciclos agrícolas.

4. Experiencias escolares (vivencias con maestros, compañeros, logros y dificultades).

5. Experiencia laboral (remuneración económica, proyectos productivos, cajas de ahorro, experiencia en cooperativas).

6. Relaciones de pareja (como conocieron a sus parejas, en qué condiciones decidieron vivir/ unirse a ellas y/o separarse.

7. Relaciones con la familia política (relaciones con los suegros, suegras, cuñadas, ejercicio de autoridad).

8. Relaciones entre pares (relaciones con mujeres y hombres de la comunidad, compañeros de trabajo, compañeros de Iglesia, entre otros).

9. Salud sexual y reproductiva (experiencia e inicio de la vida sexual, métodos de prevención y planificación familiar, experiencias alrededor del nacimiento de los hijos, tipo de atención médica recibida durante el embarazo, parto y posparto).

Estas nueve temáticas fueron las abordadas con las mujeres, las cuales transcurrían en diversos días de entrevistas, ya que había algunas más delicadas y más difíciles de expresar que otras, o había otras que requerían mucho más espacio de contención y del cuidado de la intimidad, como la de la salud sexual y reproductiva, donde por lo general las mujeres compartían desahogándose de sus experiencias de abuso. Las temáticas abordadas en las guías igual sirvieron para la elaboración de categorías analíticas para el proceso de sistematización.

\section{Contextualización: Chiapas y el ejido Zaragoza}

Chiapas sigue siendo uno de los cinco estados ${ }^{5}$ con mayores índices de pobreza y rezago social. Según el CONEVAL (2014), el 76.2\% de la población se encuentra en una situación de pobreza ${ }^{6}$, lo cual representa a 3,962 mil personas. Esto también debido al crecimiento de la población. De acuerdo con el CONEVAL (2014), el indicador que explica el incremento de la pobreza es el deterioro al ingreso familiar, que está por debajo de la línea de bienestar económico y debajo de

${ }^{5}$ En conjunto con los estados de Guerrero, Estado de México, Oaxaca y Veracruz.

6 Una persona es pobre cuando tiene un rezago en al menos uno de los 6 indicadores estimados por CONEVAL (2014): educación, acceso a servicios de salud, acceso a seguridad social, espacios de la vivienda, servicios básicos de la vivienda y acceso a la alimentación; y su ingreso está por debajo de la línea de bienestar equivalente 1,596 pesos para población rural y 2,518 pesos para urbana. 
la línea de bienestar mínimo. Sin embargo, con relación a la pobreza extrema ${ }^{7}$, hay una reducción al pasar del $32.2 \%$ al $31.8 \%$, que se debe al mayor acceso de servicios de salud, educación y espacios de vivienda.

Una de las transiciones más importantes, dadas las reestructuraciones económicas en el ámbito rural, ha sido la migración de jornaleros campesinos, lo que ha ocasionado que las mujeres asuman el rol de jefas de hogar ${ }^{8}$ y una mayor participación en la vida agraria.

El ejido Zaragoza fue fundado en 1940. La comunidad, está conformada por 1,550 habitantes, según las autoridades ejidales, de los cuales 780 son mujeres y 770 son hombres, aproximadamente. Por lo regular, su organización económica y forma de vida se sustenta en la milpa y las actividades agropecuarias, reguladas a través del conocimiento del ciclo agrícola. En las comunidades tzeltales de la Selva y en el ejido Zaragoza, quienes desempeñan los cargos son los ejidatarios y son estos los que desempeñan los cargos representativos de las comunidades, incluso son quienes pagan las festividades y rituales de la comunidad, así como son los que monitorean y regulan las actividades agrícolas.

Los tzeltales acostumbran a hablar de "lo que es nuestro", sobre todo en las reuniones y asambleas. En el trabajo cotidiano se escucha comúnmente la palabra ay ku'untik que significa lo nuestro, lo de nosotros.

El ejido se organiza a través de la producción y reproducción de las unidades domésticas a través del sistema de parentesco, el cual se caracteriza por ser patrilineal y patrivirilocal. La tierra es el elemento fundamental en torno del cual se organizan las familias, por lo que las alianzas matrimoniales se llevan a cabo entre personas del mismo ejido y por lo regular se busca que compartan la misma religión.

\section{Usos y costumbres de las campesinas tzeltales}

Los usos y costumbres se refieren a las formas propias de autogobierno de las comunidades, regidas por sistemas normativos que se actualizan a través del tiempo. Para el ejido Zaragoza, "el uso y costumbre" significan la "memoria del pueblo tzeltal que se mantiene en sus quehaceres del día a día".

Valentina, una joven del ejido Zaragoza de 17 años que era muy cercana a su abuela, me contaba:

\footnotetext{
7 Una persona se encuentra en pobreza extrema cuando tiene 3 o más carencias de los 6 indicadores mencionados antes y su ingreso está por debajo de la línea de bienestar mínimo que es de 853 pesos rural y 1225 pesos urbano.

${ }^{8}$ En el 2015 los hogares con jefatura femenina en Chiapas se acrecentaron a 300, 561, lo cual corresponde a un $24.3 \%$.
} 
Aunque me está esperando en otro mundo pue, nuestro mutil ko'tantik ${ }^{9}$ está conectado. Antes de morir, tenía su ojito así cerrado, me dijo que mi vida cambiaría cuando cumpliera los catorce, que ya tenía que buscar marido, obedecer a una nueva familia, que iba pue a cortar mi sueño y madurar antes de tiempo, que si pudiera no hiciera caso a mi madre ni a mi padre, que le hiciera caso al ch'ule/ ${ }^{10}$, Nuestro ch'ulel si sabe pue, si sabe cuándo se puede detener, cuanto se puede alargar un espacio... una sonrisa (entrevista realizada el 2 de abril de 2014).

En los ámbitos rurales, las campesinas como Valentina tienen limitados accesos a las oportunidades y a los recursos; no cuentan con las posibilidades para alargar esos años constitutivos de su desarrollo. Las niñas trabajan desde muy temprana edad en la milpa, en el cuidado de sus hermanos menores y en las tareas domésticas del hogar. De tajo, cortan sus estudios, sus ocupaciones, sus sueños y se convierten en esposas o en jóvenes madres. Además, se enfrentan a diversas desventajas y violencias instaladas para garantizar la reproducción del orden social establecido.

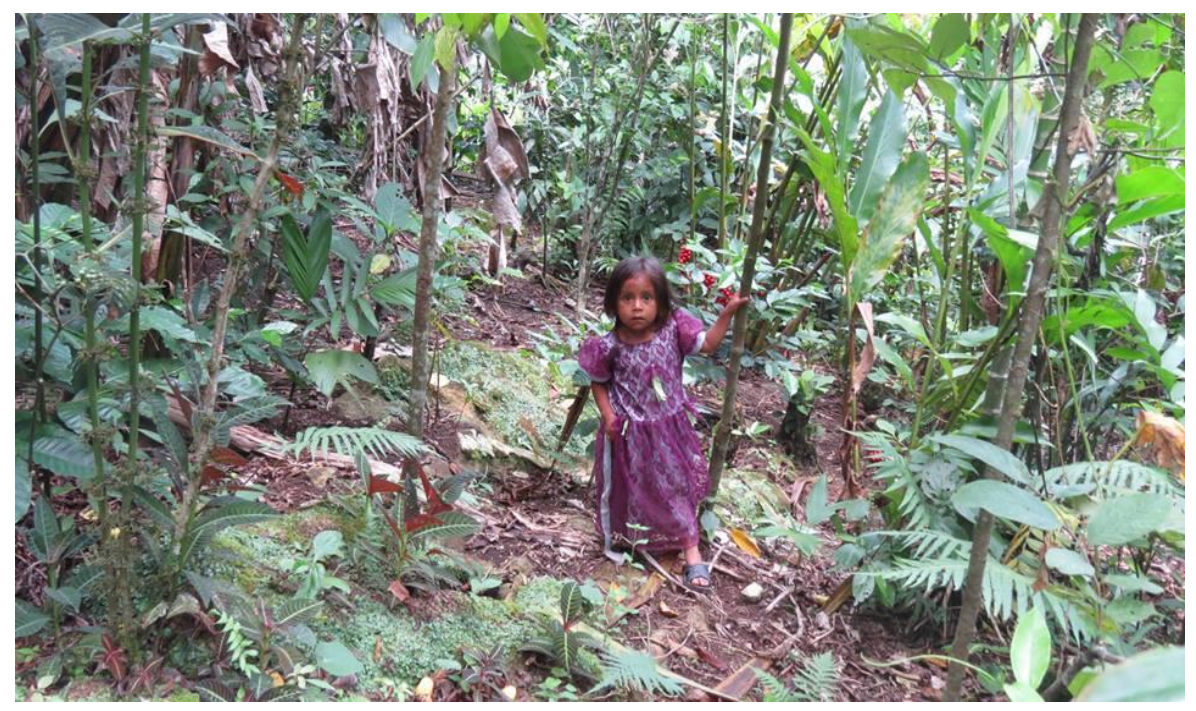

Fotografía 1. Niña del ejido Zaragoza en los cafetales. Febrero, 2014. Tomada por: Ana Georgina López.

Como hombres y mujeres tzeltales, lo más importante es el ch'ulel, el alma, lo más sagrado, que se encuentra en vínculo con el ave del corazón "mutil ko'tantik", esta ave se caracteriza por estar agitada, por tener un aleteo de intuición e inquietud que les avisa sobre lo que ocurre en el mundo y más allá de él.

Las campesinas tzeltales son generalmente mujeres delgadas, miden alrededor de 1.55 metros de altura en promedio y son de mejillas muy coloradas. Visten una falda larga azul oscura, una

${ }^{9}$ Ave del corazón para los tzeltales.

10 Alma. 
faja regularmente roja o morada de color vivo que se ajusta a un huipil colorido de tejidos de flores, o una blusa de algodón. Por lo regular usan sandalias o zapatos de goma que compran en Ocosingo. Los hombres usan pantalón de mezclilla con camisa de algodón, de manta o de cuadros y distintos tipos de botas, unas de hule para el trabajo en la milpa y otras más de tipo vaquero. En las festividades, los hombres no solamente usan su camisa de manta, sino también usan un pantalón, al que le llaman calzón, que también es de manta y un sombrero de palma.

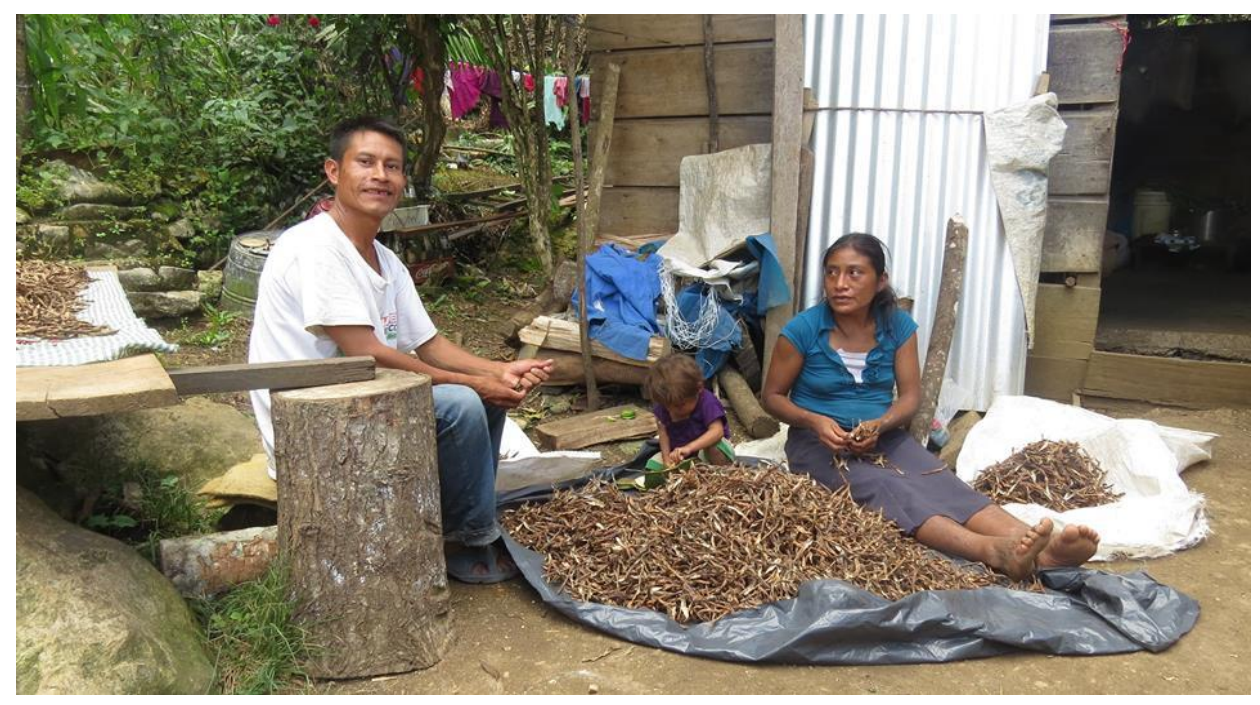

Fotografía 2. Familia tzeltal del ejido Zaragoza. Febrero, 2014. Tomada por: Ana Georgina López.

La residencia conyugal es de tipo patrivirilocal, que como señalaba Robichaux (2005), implica el inicio de la vida conyugal en la casa paterna y la herencia patrilineal. Las mujeres cargan con las labores domésticas, las que implican trabajo en el hogar (cocina, lavado, crianza a los niños), así como el cultivo de hortalizas, las actividades de traspatio y de siembra en el mismo solar que contribuyen al sustento alimenticio de la familia.

La jornada para las campesinas indígenas inicia a las 4:00hrs aproximadamente. A esa hora se ponen su falda que aprietan con una faja ajustada. Salen del cuarto donde su esposo y/o sus hijos duermen. Si hay bebés, por lo regular se los amarran con el rebozo para que sigan durmiendo. Lavan su cara, cepillan su cabello, lo agarran hacia atrás en una coleta o se lo trenzan. Encienden el fogón. Juntan la leña de forma entrecruzada y la prenden con un ligero ocote. Agregan agua a la olla y lo primero que ponen es el café.

Después, preparan el desayuno tanto para su pareja que se va a la milpa, como para el resto de la familia (propia como política). Posteriormente, comienzan a desgranar el maíz, a atender a los animales de corral y a arreglar a los niños para que se vayan a la escuela. Una vez que los niños se van, las mujeres por lo regular se quedan con sus suegras y cuñadas, o solas. Es cuando realizan la mayoría de los quehaceres de la casa, como limpiar, barrer, acarrear agua, ir a lavar la ropa de los niños, atender el traspatio y preparar el maíz para la tortilla. 
Las mujeres dedican aproximadamente dos horas diarias para acarrear el agua que utilizan para la preparación de los alimentos, para las labores del hogar y del baño. Cargan los recipientes sobre su cabeza, y van y vienen constantemente de su vivienda al caudal, y viceversa.

Cuando llegan los hijos de la escuela, es notorio cómo los niños llegan directo a jugar o a comer, y las niñas llegan a servir o a cuidar a los hermanitos más pequeños. La madre le amarra al bebé al costado y le pide asumir su cuidado mientras termina de servir la comida. Una niña me decía: "A mí no me gusta que la escuela dure tan poquito, quisiera quedarme en la tarde a jugar con mis amigas".

Posteriormente, como a eso de las cinco de la tarde llegan los maridos. Las mujeres vuelven a tortear, a calentar la comida y a tener listos los pendientes en el hogar. Las suegras suelen supervisar constantemente las actividades de las nueras. Acostumbran a indicarles si lo hacen "bien o mal" o les refieren que "eso no lo aprendieron bien en su casa", sobre todo en el caso de las más jóvenes.

Las suegras están al pendiente del humor de sus hijos con relación a cómo los atienden. Por ejemplo, me tocó escuchar a varias mujeres que expresaban cosas como: "mira pue, lo tienes contento", "se me hace que no le estás dando lo que quiere por qué se mira triste cuando llega" o "se te va a ir con este caldo tan malo, mija".

Cuando llegan de la milpa, los hombres acostumbran a descansar. Por lo regular, se relajan después de comer, miran partidos de fútbol en la televisión o aprovechan para estar con sus hijos. Las mujeres casi no se sientan en ningún momento del día. Incluso, una de mis entrevistadas llegó a agradecerme "el ratote" que nos sentamos a platicar, que porque era el tiempo donde más se acordaba haber estado sentada en una banca. Sus cuerpos son altamente productivos: siembran, cosechan, venden, distribuyen, transportan, cargan, cocinan, limpian, cuidan, crían, etc. Es como si su cuerpo debiese soportar los embates de una vida destinada al hacer y sostener. Pocos son los espacios para sentarse, para recrear, pensar o meditar.

Respecto a sus experiencias en la noche, algunas mujeres me comentaban sus conflictos y dificultades. Por ejemplo, Catalina de 21 años, me expresaba lo difícil que era tratar de dormir a su hijo de cuatro meses de nacido y tener relaciones sexuales con su esposo, sin que su bebé se despertara. En sus palabras: "Es que es necio, le he dicho que se espere, que por lo menos no me pida tanto. Estoy con la leche y se me sale, se me sale por todos lados... es feo, pero a todo una se acostumbra pue... y lo que me pesa más es que Domingo quiere que uno le satisfaga su berrinche, si así quedara bien, pero la cosa es que despertamos al niño, pue, y luego ya es pesado, es pesado dormirlo... Ilora y grita" (entrevista realizada el 22 de diciembre de 2013).

Mary, otra campesina, me decía que su esposo buscaba las relaciones sexuales casi a diario. Que a ella no le gustaban y sentía además desconfianza de él. "Es que tiene que ser diario, no me cuida. Ya tenemos tres niños y apenas tengo 22 años, no sé cuántos hijitos voy a tener a los 40 , pero voy a terminar panzona otra vez si seguimos así...tengo que cumplir pue... ya ni me gusta... a él lo único que le interesa es terminar y me dice, pero me estoy saliendo para no 
preñarte. Lo que no me gusta es que le diga a su compadre que nosotras somos como flores que hay que respetar" (entrevista realizada el 8 de diciembre de 2013).

Como se observa, los días para las mujeres son sobrecargados en quehaceres y actividades dirigidas a complacer tanto a la pareja como a la familia. No solamente tienen que cumplir los quehaceres domésticos y las labores de crianza, sino además tienen que "cumplir" con la sexualidad, aunque no exista confianza ni gusto, como lo expresaba Mary.

En el caso de las mujeres que pertenecen a cooperativa, caracterizada por ser una sociedad integrada por familias y socios de varios ejidos y comunidades, la cuál se contextualiza en el siguiente apartado; la sobrecarga de trabajo aún es mayor, sobre todo si se tiene pareja e hijos, ya que además de cumplir con las actividades en el hogar, deben asumir el rol establecido en la cooperativa, que tiene que ver con las labores en las instalaciones una o dos veces por semana, según sea el caso, para realizar los quehaceres en la producción del café (molido o envasado) o aseo del área de trabajo.

En este aspecto, las mujeres líderes de la cooperativa cafetalera, que por lo regular pasaban mayor tiempo en el módulo o viajando para distribuir su producto, presentaban dos características: o eran mujeres solteras, viudas, separadas, abandonadas, o eran mujeres de 40 años o más que ya contaban con mayor tiempo para las actividades productivas extradomésticas. Para las mujeres en etapa reproductiva (de 15 a 40 años aproximadamente) era muy difícil contar con tiempo para sí mismas, para emplearse en algún proyecto o para tener libertad.

En el ejido Zaragoza existen tres formas de iniciar la vida conyugal: la más frecuente es "huirse" con el novio; otra de ellas es mediante el rapto, que implica a la novia ser robada para tener relaciones sexuales y después juntarse con ella, y la última es unirse bajo permiso y hacer una fiesta.

Tanto en la fuga ("el huirse"), como en el rapto, la costumbre es que el novio debe pedir perdón a los papás de ella y pagar una cantidad aproximada entre los 5,000-25,000 pesos —fueron las cifras que me señalaron- por la novia, dependiendo del arreglo al que se llegue y de la edad de la novia. Cuando la pareja se une bajo permiso, se acostumbra el tiempo vigilado de noviazgo, la pedida de la novia y la planeación de la fiesta, pagada por el novio. Además, si el novio pertenece a una religión, la novia debe bautizarse y convertirse a ésta. Se unen conyugalmente, se hace una ceremonia ante la comunidad, pero no contraen matrimonio por lo civil ${ }^{11}$.

La norma de residencia es patrivirilocal, es decir, la recién pareja transita a vivir a la casa de los padres del novio y se establecen nuevos vínculos de obligaciones que involucran a toda la familia. Este periodo de residencia es obligado, antes de construir o de establecer su propia casa y su duración es variable, puede durar uno, cinco, diez, hasta quince años e implica a las nueras

11 Situación que las excluye de derechos de propiedades ejidales, de títulos agrarios y de herencias. 
hacerse cargo de las labores domésticas de la familia, cocinar y lavar para los suegros o cuñados, además de la pareja y los hijos.

La transición de mudarse de su familia nuclear a la familia política es descrita como una de las etapas más duras para las campesinas, por la sobrecarga de actividades y las expectativas que tenían cuando se unieron:

[...] creí que iba a ser distinto pue, tenía esperanza en él, en que íbamos a ser una familia bonita, que me iba a aceptar su familia, pero ha sido duro, cansado, porque no es lo mismo hacer las cosas como las pide mi mamá en casa, a cuando las pide mi suegra. Nadie defiende, nadie mete mano a fuego. Me siento sola pue, pero así es aquí, es nuestro deber como mujeres, ya hasta después nosotras tenemos esas nueritas que nos ayudan... lo más pesado fue la semana recién me junté. Hay que encontrarle el modo a lavar, triturar el maicito, hacer la tortilla, darle gusto en cómo se está educando a los hijos. Luego mi suegra nos compara todo el tiempo a mis cuñadas y a mí, ya decimos entre broma y broma (ríe), pues tiene su favorita para cada quehacer (Catalina, 21 años, entrevista realizada el 22 de diciembre de 2013).

Así pues, se expulsan a las hijas y se adquieren a las nueras como nuevos elementos para el trabajo productivo y reproductivo. Igualmente, las normas de residencia conyugal limitan las oportunidades de estudio para las mujeres rurales y se vinculan a la condición de la residencia patrivirilocal descrita anteriormente, donde se legitima más su cumplimiento como nuera, compañera y madre. No se les motiva a desarrollarse en este aspecto, ni se vislumbra al estudio como una necesidad primordial. Es común que las jóvenes se junten conyugalmente al terminar la telesecundaria o incluso antes, entre los 14 y los 15 años.

Al compartir la residencia, las campesinas deben actuar conforme a las normas familiares que consisten en obedecer a sus suegros, atender a sus maridos, realizar las labores domésticas y las cargas de trabajo agrícola, así como cumplir con la procreación y el cuidado de los hijos.

Por lo general la suegra es la guardiana de la costumbre, es quien se encarga de supervisar la realización de las tareas domésticas de la nuera, así como el control de su movilidad, la vigilancia hacia sus salidas y las interacciones que mantiene.

[...] Doña Lucha me ponía a lavar todo lo de sus hijos, hasta sus calzones, me inventaba chismes y me aventaba los frijoles diciéndome que no sabían bien, que a su hijo no le iban a gustar... me regañaba cuando saludaba a otras personas, incluso si era mi familia...se enojaba, decía tú ya vives con nosotros...te quieres largar Maca... te quieres devolver pue (Macaria, 40 años, entrevista realizada el 4 de marzo de 2014).

Como se observa, el sistema de parentesco incide en la conformación de la organización social en conjunto con las categorías de género y generacionales en donde se articulan las relaciones de poder a través de normas de residencia conyugal y reglas de herencia que mantienen ciertas jerarquías y posiciones al interior de la unidad doméstica. 
Para Bestard (1998) las redes de reciprocidad configuran a las comunidades a través de las unidades familiares que se organizan a través de las alianzas de parejas, para asegurar la reproducción de los grupos, así como la permanencia de mujeres como fuerza productivareproductiva de trabajo.

\section{En la construcción de los procesos de agencia, a través de la cooperativa}

Recupero la noción de agencia, dadas las diferentes respuestas obtenidas en el trabajo de campo por parte de las campesinas cafetaleras del ejido Zaragoza, quienes, a pesar de tener condiciones de violencia en su contra, ejercen su poder a través de ciertas relaciones y situaciones que les permiten generar diversas alternativas de mejora a sus realidades cotidianas.

Estos procesos, como argumenta Zapata (1998), han tenido que ver con los cambios intergeneracionales y socioeconómicos señalados anteriormente, en donde las mujeres indígenas se han incorporado a diversos tipos de organizaciones, asociaciones y empleos, en los cuales se establecen distintas mediaciones, prácticas, toma de decisiones, administración de recursos y capacidad de relación en el ejercicio de poder. En la agencia, el sujeto se sitúa en su capacidad de actuar, no como individual, sino en el vínculo con lo relacional del poder. Giddens (1986) define a la agencia como:

Agencia se refiere no a las intenciones que la gente tiene en hacer cosas, sí a su capacidad de hacer esas cosas en primer lugar -por ello la agencia implica poderAgencia se refiere a los eventos de los cuales un individuo podría, en cualquier fase de una secuencia de conducta, haber actuado de manera diferente (Giddens, 1986: 9).

Asimismo, la capacidad de agencia, la capacidad de ejercer o subvertir el poder, tiene que ver con las conexiones, con los tipos de alianzas, vínculos, relaciones o intermediaciones establecidas. Giddens propone el análisis de esas situaciones de co-presencia, de serialidad de encuentros, en conjunto con el posicionamiento del cuerpo y la reflexividad del agente sobre sus procesos de rutinización, sus repeticiones de prácticas que le dan sentido. Para mí, la agencia significa el despliegue de la capacidad relacional, -con conciencia y reflexividad-, para llevar a cabo los objetivos propuestos. A la vez, la agencia va de la mano con la construcción de capacidades, fundamentada en Sen (1990) como aquellas habilidades, funciones y condiciones básicas de la vida que deben estar para la expansión de la agencia.

Ahora bien, analizar estos procesos de agencia en las mujeres, sobre todo en estos contextos, implica un gran desafío. Las historias de las mujeres reflejan diversos tipos de agencias, capacidades y repercusiones, que de alguna manera dan cuenta de pequeños cambios y de una serie de posiciones en las relaciones y prácticas en el ámbito rural. Estos espacios específicos de convivencia entre mujeres permiten generar mayores ingresos, aprender oficios y resignificar su identidad a través de reconocerse en otras. Las mujeres, a través de las cooperativas, han defendido el derecho a decidir por ellas mismas la manera en que quieren trabajar, la distribución de sus actividades y sus salarios, así como la reivindicación de su participación en los espacios públicos. 
La noción de agencia es una herramienta teórica útil para poder dar cuenta de los procesos que las campesinas han ido ganando, sobre todo, en el espacio de la cooperativa. La agencia social implica poder en el sentido de una aptitud transformadora, "una acción nace de la aptitud del individuo para "producir una diferencia» en un estado de cosas o sucesos pre existentes" (Giddens, 2006: 51).

\subsection{La cooperativa como alternativa de agencia}

La producción cafetalera del ejido Zaragoza es una de las actividades económicas más importantes de la población. De hecho, el ejido aglutina a la mayoría de los socios de la cooperativa de la Sociedad de Productores Orgánicos de la Selva Lacandona (SPOSEL), más otros socios de comunidades vecinas y ejidos aledaños. De SPOSEL ${ }^{12}$, se desprende Nich Capeel, "Flor de café", cooperativa conformada por dieciocho campesinas indígenas del ejido.

El grupo de mujeres Nich Capeel "Flor de café" en tzeltal, inició en el 2004 como suborganización de SPOSEL, por iniciativa de los socios ejidatarios, quienes señalaban la importancia de diferenciarse en el mercado a través de la integración del trabajo de las mujeres. De ahí, pensaron en que una de las maneras, además de importar el café a otros países, sería la de generar una marca de café donde aparecieran las mujeres como las principales productoras, encargadas del molido y envasado. Surge la marca de café "Najá", caracterizado por ser un café orgánico de altura, con tueste afrutado. Las mujeres de la cooperativa reconocen que este espacio les ha permitido permanecer unidas y les ha generado motivación para enfrentar los obstáculos que viven en lo cotidiano. Entre sus logros destacan las capacitaciones a las que han acudido, no únicamente respecto al café, sino las que tienen que ver con la diversificación productiva para la generación de otras alternativas de ingreso.

\footnotetext{
12 La sociedad de SPOSEL surge en el año 2002. En 2013, el número de socios se incrementó hasta los 665, multiplicando el acopio de café de comunidades y localidades aledañas: Monte Azul, Monte Líbano, Copropiedad Caribal, Taniperla, Agua Azul, Perla de Acapulco, Emiliano Zapata, La Culebra, San Jerónimo, Nueva Provincia, San Juan Tzeltal, Santa Rita, Peña Limonar, Zapotal, Santa Elena y Pichucalco, del Municipio de Ocosingo; Pamal Navil, San Miguel Canxanil, Chajtetic, Nueva Orizaba, Saquiljá, San Esteban y Chilón, del Municipio de Chilón.
} 
Revista Punto Género N.ำ 9. Junio de 2018

ISSN 0719-0417 / 39 - 64

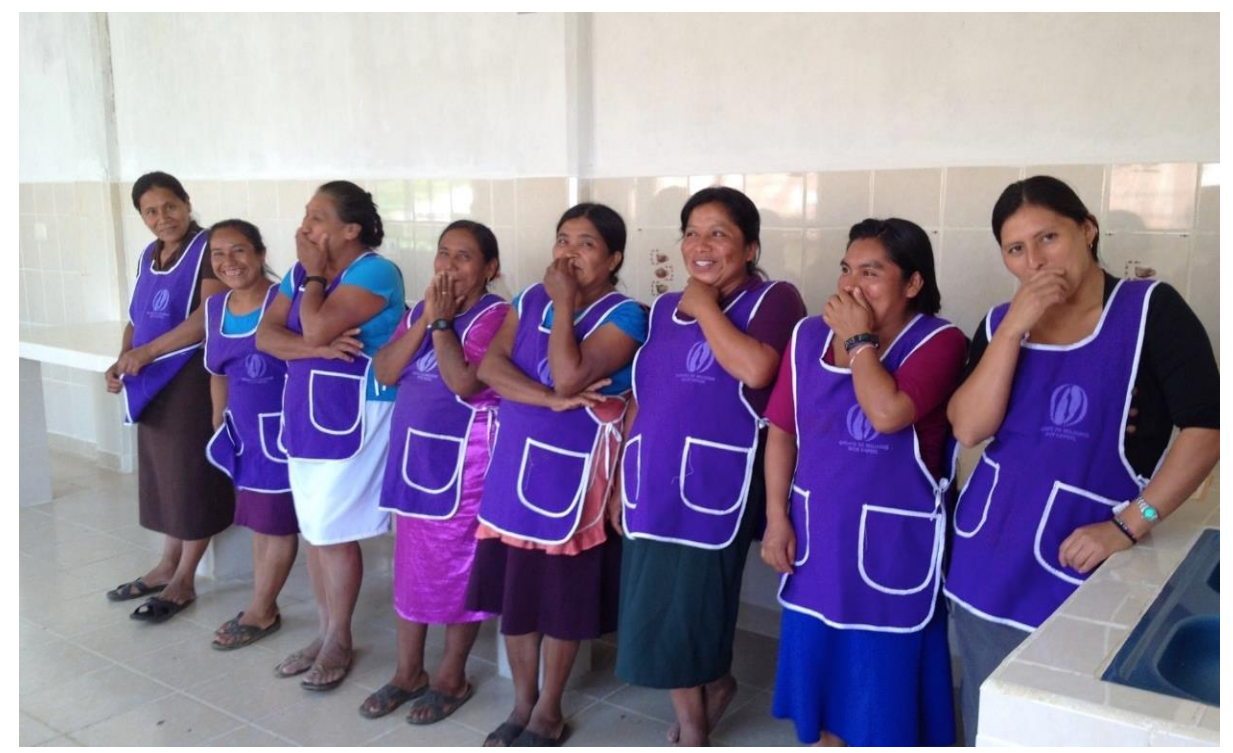

Fotografía 3. Riendo en las instalaciones. Diciembre, 2013. Fotografía de Ana Georgina López.

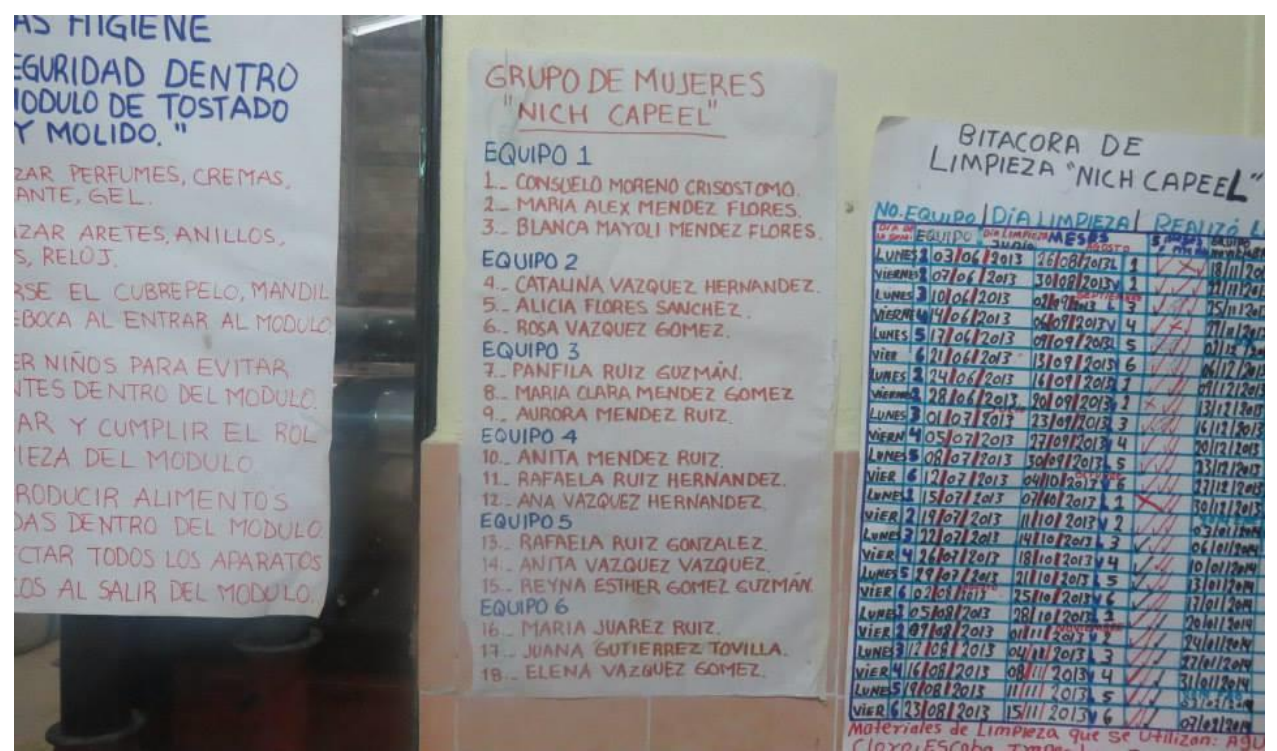

Fotografía 4. Roles y equipos de Nich Capeel. Noviembre, 2013. Fotografía de Ana Georgina López. 


\title{
6.2 Dos historias en relación al trabajo de la cooperativa: Consuelo y Anita
}

\author{
Consuelo: comerciante, panadera, costurera y cafetalera
}

Consuelo es una campesina cafetalera de 43 años originaria de Zaragoza y perteneciente a la cooperativa de Nich Capeel. Antes llegó a ser la Presidenta de la sociedad cooperativa. Creció al lado de sus hermanas y estudió hasta la primaria. Sabe leer y escribir. Sus ojos son rasgados, su tono de voz es suave y tiende a hacer bromas la mayor parte del tiempo. Actualmente, además de estar en Nich Capee/ se dedica a vender y confeccionar ropa, pan de plátano y a atender una tienda de abarrotes. Tiene cuatro hijos, tres mujeres y un hombre. Vive con su esposo, Pepe, el cual trabaja eventualmente haciendo viajes al municipio de Ocosingo para surtir la tienda que tienen.

Su jornada laboral inicia aproximadamente a las 4:00 horas. Acostumbra acarrear la leña para preparar el café y amasar el nixtamal para las tortillas, además de poner los frijoles y hacer el pozol.

Dado que se organizan en equipos de tres, a Consuelo le toca ir un día a la semana con otras dos compañeras. Ese día -si hay pedido- gana $\$ 60.00$ pesos y si no lo hay, tiene que ir a realizar el aseo y organizar el espacio. Además, tiene que ir otro día a la junta semanal que se convoca para cuestiones de información, toma de decisiones o asuntos que tratar.

Consuelo, hace tres cosas a la vez casi todas las tardes: despacha la tienda, cose en su máquina e hilvana, y está pendiente a la novela. Ya por la noche, Consuelo comienza a sentirse intranquila, porque llega su esposo Pepe, en la mayoría de las veces muy tomado. En esos momentos, a veces encierra a sus hijas en un cuarto, cierra la tienda y se pone a hacer de cenar. Ella dice que muchas veces ha querido dejarlo, pero que no se atreve. También señala las tensiones que ha vivido con su suegro. Su experiencia la narra mientras teje en su máquina:

[...] esta maquinita me la regaló mi suegro hace mucho. No muy quería... (ríe) pero me dijo: mira, Chelo, para que te entretengas, para que después puedas hacernos alguna ropita, y sobre todo para los niños y sobrinitos. $Y$ si... yo pensé que al principio iba a ser para eso. Mi suegro entonces no quería que yo atendiera la tienda que tenemos, no quería que platicara con la gente y cuando me dio la máquina fue como para que me entretuviera, como con el pan, como ya viste aprendí a hacer diferentes recetas, ahora ya soy famosa por mi pan de plátano, bueno famosa solo aquí, en Zaragoza (ríe) (Consuelo, 43 años, entrevista realizada el 11 de enero de 2014).

[...] cuando recién me casé me fue muy mal, mis suegros me recibieron contentos, pero sí eran duros. Me dijeron: Cheli, vas a seguir las reglas. Cuando nos juntamos salió Pepe de verdad, y es que el vicio siempre ha sido su pecado, su culpa más grande y ya él no lo puede controlar. Mi suegro al principio no quería que me viera nadie, hasta una vez la comadre de una amiga me dijo: pues ni te conozco, ni sales desde que te juntaste. Pero no nomasito es no salir, sino que no da tiempo de nada por todos los quehaceres. Después pasó lo de la máquina de coser. Pensé en hacer negocio, primero a escondidas, 
le comencé a decir a una comadrita que me visitaba, Lucita ahí tienes los uniformes de los niños, antes les pedían ir en azulito, entonces les mandaba pantalones. Fue así como me empezaron a dar encargos, gracias a mi comadre. Ya después les llegó el chisme a Pepe y a mis suegros. Se molestaron, me pusieron la mano encima, pero después lo vieron bien, porque estaba generando un ingreso (Consuelo, 43 años, entrevista realizada el 11 de enero de 2014).

Consuelo pensó en salirse de la cooperativa, porque ya no aguantaba el maltrato físico y sexual de Pepe y la vigilancia por parte de su suegro. Sobre todo también porque se sentía muy cansada de tantos quehaceres, ya que expresaba que si no trabajaba un día, las consecuencias las pagaba toda la familia, y "que ni si quiera él, podía tener su trago". Sin embargo, no lo hizo gracias a que las mujeres de la cooperativa la apoyaron y la acompañaron a denunciar con los socios de SPOSEL su situación. Otro aspecto que menciona Consuelo -que ha podido vivir gracias a la cooperativa- es la experiencia de los viajes, en la cual señala lo siguiente:

Con mi amiga me fui, me pidió acompañarla a Monterrey en avión para una exposición de café. Pasé pensando si iba durante toda la semana. Soñé que me subía en el avión, que veía las nubes, no dormía, ¿pero ¿cómo dejaba a Pepe tirado en la casa? Pensé no ir, pero fui débil, primero Dios y me ganaron las ganas, pue, total, me vaya o no, él va a estar tirado... (ríe) me fui con pendientito, pero en el avión ya no quería bajar, me sentí feliz, lo mejor que me ha pasado, que gracias a la cooperativa conocí (Consuelo, 43 años, entrevista realizada el 11 de enero de 2014).

Las relaciones de género-generacionales que se establecen de acuerdo al orden familiar comunitario, restringen a las mujeres en sus posibilidades de despliegue, ya que además de fomentar la dependencia económica hacia ellos, legitiman el comportamiento de hombres, en los que pueden ser abusivos o tener problemas de alcoholismo. Sin embargo, cuando Consuelo se da cuenta de que puede irse, dejarlo una semana y de que su presencia no cambia el estado de alcoholismo de su esposo, se siente liberada y decidida a disfrutar una experiencia por la cual ha trabajado.

\section{Anita: tesorera y representante del grupo}

Anita es una campesina cafetalera de 34 años perteneciente a la cooperativa de Nich Capeel. Su función es de tesorera y de representante del grupo. Mide menos de 1.50 metros, es delgada y morena, de cabello café lacio. Tiene una hija de siete años. Acabó la secundaria. Vive con su mamá y con su hija, al lado de casa de su hermano y su cuñada. Viaja frecuentemente a Ocosingo para visitar a su otra hermana que está casada y vive allá. Se encuentra separada, su pareja la abandonó cuando estaba embarazada. Respecto a ello, refiere que vivía con su pareja en Ocosingo, que un día -en los primeros meses de embarazo- Jerónimo, su pareja, desapareció por varios meses, hasta que se lo encontró con otra señora y familia. Desde ahí, Anita regresó al ejido Zaragoza y buscó otras alternativas para salir adelante. Desde su inicio, supo que el pertenecer a la cooperativa significaba una oportunidad para generar más ingresos económicos, los cuales necesitaba para mantener a su hija y apoyar a su mamá. 
[...] Sí mi papá nos maltrataba o nos pegaba era porque era muy culpa mía, siempre de chica me salía mucho de mi casa, iba a la tienda a comprar totis después de la escuela... (ríe) casi igual a como soy ahora, que siempre me gustó salir. Un día me puse a pensar, pero yo necesito zapatos, quiero tener un cambio de ropa distinto a las otras muchachas. Viajaba a Ocosingo, allá vive mi hermana pue, y una vez vi un zapatito así de piel tan bonito. Me fui mejor para trabajar allá, y me agarraron así sin saber nada, de criada de una señora. En ese momento no sabía escribir, hubiera querido saberlo, tener una libreta y anotar pasos. Pero aprendí a observar, como muchas cosas, desde niña. En Ocosingo, pude estudiar la secundaria y ahí por ese tiempo, conocí al Jerónimo (ríe)... ahora me da risa, pue... pero me dolió mucho mi ch'ulel, pue... mi hermanita y yo fuimos muy unidas a mi hermano y a mi mamá y juntos salimos adelante en ese tiempo. Me apoyaron mucho... mi hermano desde chico nos sacó adelante, desde que era niño vendía sacos de frijolito, de maicito, de lo que fuera, le aprendimos (Anita, 34 años, entrevista realizada el 14 de diciembre de 2013).

Anita además me comentó que se sentía muy diferente a sus compañeras de la comunidad e incluso diferente al interior de la cooperativa. Me comentó que en una ocasión hablaba con una amiga y llegaron a la conclusión de que en Zaragoza la mujer tiene que ser lo que todos esperan: la buena madre, buena nuera, buena esposa y buena hija.

Una de las situaciones comentadas por Anita que afecta a todas sus compañeras de Nich Capeel es que se encuentran en edades distintas, donde tienen que asumir las responsabilidades propias de cada etapa, y donde según Anita, "el peso de las actividades recae siempre en las mismas personas... pero nos apoyamos y si una señora tiene un problema la ayudo".

\section{A manera de conclusión: la agencia, el tejido de las redes entre mujeres y las alianzas establecidas}

En los ámbitos rurales se conjuntan diversas restricciones hacia las campesinas, entre las cuales están: la sobrecarga de trabajo tanto en las actividades domésticas como extra-domésticas, la vigilancia y control hacia su movilidad, la violación de sus derechos sexuales y reproductivos, así como restricciones de acceso a propiedades ejidales o a tener oportunidades laborales, que se asocian a formas de violencias interrelacionadas entre sí y a las etapas de los ciclos vitales de acuerdo a la organización social comunitaria.

Sin embargo, también existen cambios con relación al ingreso económico, la generación de capacidades y las relaciones de género en las mujeres pertenecientes a cooperativa cafetalera, que corrompen al orden normativo establecido. Es decir, existen también condiciones para el desarrollo de capacidades y formas de acceder a los recursos para las mujeres, partiendo de que el ingreso económico, la movilidad y el unirse con otras mujeres pudiera repercutir de manera significativa en su vida.

Como puede observarse en los casos anteriores, existen diversas maneras de construir capacidades y agencia, según las historias de las mujeres y la posibilidad de generar lazos y 
reciprocidades, aún a pesar de las tensiones y conflictos que las campesinas viven en estos espacios productivos. De acuerdo con Nussbaum (2002), a pesar de que estas mujeres se encuentran en una situación vulnerable, intentan transformar sus realidades a través de las relaciones y vínculos que establecen. De la misma forma, estas campesinas líderes han aprendido a negociar y a hacer alianzas con los hombres, tanto con los de SPOSEL, como con los ejidatarios.

Las campesinas también han desarrollado un proceso de toma de conciencia y reflexividad. Es decir, una capacidad para apropiarse de sus prácticas y del contexto en que éstas se generan. Anita señalaba que cuando "las señoras veían la utilidad de saber los egresos, ingresos y utilidades en la cooperativa, expresaban sus ganas por estudiar, por saber más, por ser capaces de sacar bien las cuentas".

El hecho de pertenecer a la sociedad cooperativa abre posibilidades hacia las campesinas, que antes no tenían, entre las que se encontraron: la posibilidad de estar trabajando en actividades distintas que van hacia un objetivo común, la generación de ingreso económico y las reciprocidades que surgen en los vínculos entre las mujeres.

Así pues, esta situación va mucho más allá del empoderamiento externo hacia las mujeres y tiene que ver con construir el capital social de las mujeres en sus alianzas, redes y reciprocidades para generar la agencia colectiva. Ahora bien, en los ámbitos rurales se requiere de la articulación entre el sistema normativo -los usos y costumbres comunitarios- y el apoyo al desarrollo de habilidades y capacidades en las mujeres. Mientras esto no sea confrontado, las campesinas seguirán exponiéndose a relaciones de violencia por transgredir al "orden social" y no existirán transformaciones de raíz en su situación de desigualdad. La agencia entonces aparece como un recoveco de posibilidad, en tanto pueda romper con la interiorización de las normas culturales asumidas y con la resistencia ante las condiciones de desigualdad. 


\section{Bibliografía}

Arias, Patricia (2009): Del arraigo a la diáspora. Dilemas de la familia rural. Guadalajara: Universidad de Guadalajara.

Barth, Frederick (1976): Los grupos étnicos y sus fronteras. México: FCE.

Benería, Lourdes (1982): Women and development - the sexual division of labor in rural societies: a study. New York, N.Y: Praeger.

Bestard, Joan (1998): Parentesco y modernidad. Barcelona: Paidós.

Cernea, Michael (1995): Primero la gente. Variables sociológicas en el desarrollo rural, México, DF: Fondo de Cultura Económica.

CONEVAL (2014): Estimaciones de la pobreza en México. En:

http://www.coneval.gob.mx/Medicion/MP/Paginas/Pobreza_2014.aspx

De la Cadena, Marisol (1992): "Las mujeres son más indias". Espejos y travesías, No. 16 pp. 25 Tomado de: http://www.bdigital.unal.edu.co/43636/1/Espejosytravesias.pdf al día: 14 de noviembre de 2103.

De Sousa Santos, Boaventura (2000): Descolonizar el saber, reinventar el poder. Ediciones Trilce, Montevideo, Uruguay.

Echeverri, Rafael y María Pilar (2002): Nueva ruralidad. Visión del territorio en América Latina y el Caribe, San José de Costa Rica. Instituto Interamericano de Cooperación para la Agricultura, Centro Internacional de Desarrollo Rural, Corporación Latinoamericana Misión Rural.

Freyermuth, Graciela (1997): "Muerte materna, género y etnia en Chenalhó", en Nueva Antropología, vol. 16, núm. 52-53.

(2004): "La violencia de género como factor de riesgo en la maternidad", en Torres, Marta [comp.], Violencia contra las mujeres en contextos urbanos y rurales, México: El Colegio de México.

Giddens, Anthony (1986): The constitution of society. Cambridge: Polity Press.

(2006): "Estructura, sistema, reproducción social" en La constitución de la sociedad. Bases para una teoría de la estructuración. Buenos Aires: Amorrortu, pp. 193-253.

Glaser, B. y Strauss A. (1967): The discovery of grounded theory: Strategies for qualitative research. New York: Aldine publishing. 
González Montes, Soledad (1993): "Hacia una antropología de las relaciones de género en América Latina" en Soledad Gonzáles (coord.) Mujeres y relaciones de género en la antropología latinoamericana. El Colegio de México. México.

(2002): "Las mujeres y las relaciones de género en las investigaciones sobre el México campesino e indígena", en Urrutia, Elena [coord.], Estudios sobre las mujeres y las relaciones de género en México: aportes desde diversas disciplinas, México: El Colegio de México.

Lagarde, Marcela (1992): Identidad de género, feminidad y masculinidad. Colección Alternativa.

Lamas, Marta (1995): “Usos, dificultades y posibilidades de la categoría de género" en Revista de Estudios de Género La Ventana, Núm. 1, junio, México, Universidad de Guadalajara.

Marroni, Ma. Da Gloria (1995): “Trabajo rural femenino y relaciones de género" en Relaciones de género y transformaciones agrarias, El Colegio de México, pp. 135-162.

Martínez Carazo, Piedad C. (2011): "El método de estudio de caso. Estrategia metodológica de la investigación científica". Universidad del Norte. Consultado el 25 de febrero de 2011. http://docs.google.com/viewer?a=v\&q=cache:e319FmqT4scJ:ciruelo.uninorte.edu.co/pdf

Mummert, Gail. (1995): "El proceso de incorporación de la mujer al mercado de trabajo: tres cohortes de obreras, maestras y comerciantes del valle de Zacapu, Michoacán". S. González Montes y V. Salles (coords.), Relaciones de género y transformaciones agrarias, PIEM, El Colegio de México, 53-89.

Nussbaum, Martha (2002): Las mujeres y el desarrollo humano. Barcelona: Herder.

Olivera, Mercedes (2001): "Mujeres indígenas de México", Mujeres indígenas, seminario de GIMTRAP, México.

Ortner, Sherry (1984): "Theory in Anthropology since the Sixties". Comparative studies in society and history, 26(1), 126-166.

Radcliffe-Brown, A. (1974): "Sobre las relaciones burlescas" en Estructura y función en la sociedad primitiva. Barcelona: Península, 107-123.

Robichaux, David (1997). "Un modelo de familia para el México Profundo", en Espacios familiares: Ámbitos de sobrevivencia y solidaridad, Investigación sobre las Familias y los Fenómenos Sociales Emergentes en México, México, PUEG/UNAM/ DIF/CONAPO/UAMAzcapotzalco.

antropológicas. México: Iberoamericana. 
Revista Punto Género N․⒐ 9. Junio de 2018

ISSN 0719-0417 / 39 - 64

Ruiz Massieu, Mario (1987): Derecho Agrario Revolucionario. México: UNAM.

Scott, Joan W. (1986). “El género: una categoría útil para el análisis histórico”. Historical review, 91, 1053-1075.

Sen Amartya (1990): "Gender and Cooperative Conflict" en Irene Tinker (comp)., Persistent JnequaJities, Nueva York: Oxford University Press".

Valderrama, Ponce M. (2006): "El cuidado, ¿una tarea de mujeres?” Cuadernos de HistoriaGeografía, 35, pp. 373-385.

Zapata, Emma (1998). "Las Organizaciones no gubernamentales (ONG) y el "empoderamiento" de las mujeres", en González, M. y M. Núñez (coords.), Mujeres, género y desarrollo, Morelia: EMAS, CIDEM, Universidad Autónoma de Chiapas. 